\title{
Images polyvalentes de saint Martin de Tours dans le contexte médiéval
}

Multifunctional images of St Martin in the Middle Ages

\section{Etelvina Fernández González}

Traducteur : Laurey Braguier

\section{(2) OpenEdition}

\section{Journals}

\section{Édition électronique}

URL : http://journals.openedition.org/abpo/2479

DOI : $10.4000 /$ abpo. 2479

ISBN : 978-2-7535-2136-0

ISSN : 2108-6443

Éditeur

Presses universitaires de Rennes

\section{Édition imprimée}

Date de publication : 30 octobre 2012

Pagination : 108-129

ISBN : 978-2-7535-2134-6

ISSN : 0399-0826

Référence électronique

Etelvina Fernández González, « Images polyvalentes de saint Martin de Tours dans le contexte médiéval », Annales de Bretagne et des Pays de l'Ouest [En ligne], 119-3 | 2012, mis en ligne le 30 octobre 2014, consulté le 02 mai 2019. URL : http://journals.openedition.org/abpo/2479; DOI : 10.4000/ abpo. 2479 


\title{
Images polyvalentes de saint Martin de Tours dans le contexte médiéval
}

\author{
Etelvina Fernández GonZÁLEZ \\ Institut d'Études Médiévales - Université de León (Espagne) \\ Traduction Laurey BRAGUIER
}

Dans cette brève étude sur saint Martin de Tours, il s'agira de nous intéresser plus précisément à la connaissance des abbayes et des centres martiniens à partir de textes et d'images. Pour cela, nous nous appuierons sur diverses œuvres artistiques provenant de plusieurs périodes chronologiques et exécutées avec différentes techniques et sur des supports variés ${ }^{1}$. Nous nous intéresserons à l'ensemble des manifestations textuelles et plastiques puisqu'elles générèrent un contexte propice dans lequel se développa et se diffusa au cours des siècles la dévotion martinienne. Compte tenu de l'ampleur de ce sujet, nous nous limiterons au début du XIII ${ }^{\mathrm{e}}$ siècle.

Ses œuvres participèrent à élever la figure de saint Martin à un rang prééminent dans l'hagiographie médiévale de toute l'Europe ${ }^{2}$; ce qui fut en bonne partie favorisé par la piété des fidèles et le soutien de la royauté3.

1. Ce travail a été rédigé en février 2009. D’autres travaux ont été réalisés sur saint Martin de Tours et le chemin de Saint-Jacques-de-Compostelle; en particulier FERNÁNDEZ GonzÁLEz, Etelvina, "San Martín de Tours en el Camino de Santiago : culto, advocación e iconografía en la Edad Media ", El camí de Sant Jaume i Catalunya. Actes del Congrés International celebrat a Barcelona, Cervera i Lleida, els dies 16, 17 i 18 d'octubre de 2003, Abadía de Montserrat, 2007, p. 221-238, qui est la source des réflexions du présent travail.

2. SULPICE SÉVÈRE, Obras completas, étude préliminaire et traduction de Carmen Codoñer, Madrid, 1987; (À présent, nous emploierons Vie pour les références se rapportant à cette édition); Venance Fortunat, Vita Martini, Opera poetica, Patrologia Latina, cité par Sauvel, Tony "Les miracles de Saint-Martin : Recherches sur les peintures murales de Tours aux ve et $\mathrm{VI}^{\mathrm{e}}$ siècles ", Bulletin Monumental, 114, 1956, p. 153-179; JACQUES DE VoRAGINE, La Légende dorée, Roze, J.-B. M. (trad.) t. II, Paris, 1967, p. 336-346; LECOY DE LA MARCHE, Albert, Saint Martin, Tours, 1890; RÉAU, Louis, Iconografía del arte cristiano. Iconografía de los santos, t. 2, vol. 4, Barcelone, 1997, p. 349; Lexikon der Christlichen ikonographie, Vox, "Martin von Tours ", t. 7, Rom, Freiburg, Basel, Wien, 1974, cols. 752-579; LinAJE CONDE, Antonio, « En el presentimiento de Europa : San Martín de Tours entre el monasterio y la diócesis ", Santos, obispos y reliquias, Alcalá de Henares, 1998, p. 9-35 et PRICOCO, Salvatore, "Culto dei santi e delle reliquia nell'età di Teodosio : Martino di Tours, Ambrosio di Milano ", Santos, obispos y reliquias, p. 35-45.

3. Corbet, Patrick, Les Saints ottoniens. Sainteté dynastique, Sainteté royale et Sainteté féminine autour de l'an Mil, Sigmaringen, 1986, dans cet ouvrage est analysée la figure 


\section{" Images " littéraires}

La péninsule ibérique n'est pas étrangère à cette situation et rapidement le culte de saint Martin s'est propagé sur l'ensemble du territoire hispanique $^{4}$. Les anciens textes liturgiques le confirment. En effet dans l'Oracional de Vérone qui représente la tradition liturgique hispanique du $\mathrm{VII}^{\mathrm{e}}$ siècle, la fête de saint Martin est présente au coté de celle de saint Saturnin, autre saint de la Gaule ${ }^{5}$. De la même manière, dans le texte du Liber Ordinum de Silos, il est fait référence à trois fêtes en son honneur : la translatio $^{6}$, la consacratio $^{7}$ et l'obitus ${ }^{8}$. La fête a été insérée plus tard dans l'Antifonario de la cathédrale de León ${ }^{9}$.

de l'impératrice Adélaïde et le sens de la dignitas royale et de l'humilitas chrétienne, vertus particulièrement appréciées par la souveraine, comme en témoigne le texte de son ephitaphium.

4. García Rodríguez, Carmen, El culto a los santos en la España romana y visigoda, Madrid, 1966, Apend. $n^{\circ}$ 108, p. 43-144 et FERnÁNDEZ GonZÁLEZ, Etelvina, "San Martín de Tours en el camino de Santiago... ", op. cit. Pour cette raison, il n'est pas rare, depuis le milieu du IV ${ }^{\mathrm{e}}$ siècle, époque où se propage le culte martinien sur les terres de la péninsule, de trouver d'abondantes références aux reliques, autels et temples qui lui sont consacrés. Cela a été en s'accentuant au cours des siècles et cela s'est maintenu jusqu'au Xvi ${ }^{\mathrm{e}}$ siècle, voir : FERnÁndez GonZÁlez, Etelvina, "San Martín de Tours en el camino de Santiago... ", op. cit, p. 223-227. Il faudrait ajouter les miracles réalisés par le saint sur les terres hispaniques et le rayonnement de la fête du 11 novembre, date qui clôt le cycle annuel agraire.

5. Oracional visigótico, VIVEs José et CALAVERAS, J. (éd.), Barcelone, 1946, p. XXIV-XXV et 384-388. Pour une plus grande connaissance de ces sujets, nous renvoyons à : MELERO Moneo, Marisa, "Saint Saturnin en Espagne : culte et iconographie en Navarre ", dans : Saint Jacques et la France, (Actes du Colloque des 18 et 19 janvier 2001 à la Fondation Singer-Polignac), Paris 2003, p. 287-319; OrRIOLS I ALSINA, Anna, " Hagiographie et art roman en Catalogne ", Les Cahiers de Saint-Michel de Cuixa, XXIX, 1998, p. 121-141, en particulier p. 125-127 et EsPañol, Francesca, "San Leonardo en los reinos hispánicos : culto e iconografía ", D’une Montagne à l'autre. Études comparées, Grenoble, 2001, p. 243-273.

6. FÉRotin, Marius, Le Liber Ordinum en usage dans l'église wisigothique et mozarabe d'Espagne du cinquième au onzième siècle, Paris 1904, réimpr. Rome, 1996, cols. 470-471. L'auteur précise que cette fête est citée dans les manuscrits des années 1039, 1052, 1055, 1067 et 1072.

7. Ibidem., cols. 474-475. Cette fête est présente dans les manuscrits des années 1039, 1052, 1066, 1067 et 1072, et dans Liber ordinum sacerdotal, édition de JANINI, José, Burgos, 1982, p. 20. Dans un autre manuscrit de Silos est inclus le texte pertinent dans In Festivitate Sancti Martini episcopi, après celui de : In Natale Sancti Martini Confessoris, Londres, British Library, Add. Ms. 30849 et voir : WALKER, Rose, Views of Transition. Liturgy and Illumination in Medieval Spain, Toronto, 1998, p. 163.

8. FÉrotin, Marius, op. cit., cols. 486-487. La fête est notée dans les manuscrits des années : 1039, 1052, 1055, 1066, 1067 et 1072. Dans le codex vigilanus de l'année 976, on intègre la fête de saint Martin le 11 novembre; El Escorial, Biblioteca del Real Monasterio, Ms. d. I. 2, fol. 6.

9. Antifonario visigótico-mozárabe de la Catedral de León, BROU Louis. et VIVES, José. (éd.), Madrid, 1959. Sont insérés l'Officium in diem sacrationis Martini (ad vesperum), $\mathrm{f}^{\circ} 231 \mathrm{r}^{\circ}$ et $\mathrm{v}^{\circ}$, t. I, p. 387-389 puis la messe et l'Officium in diem sancti Martini Aep(iscopi) (Ad vesperum III idus n(ovem)b., $\mathrm{f}^{\circ} 244 \mathrm{r}^{\circ}-246 \mathrm{r}^{\circ}$, p. 407-412. On peut également consulter l'édition fac-similée de ce codex : Liber Antiphonarium de toto anni circulo a festivitate sancti Aciscli usque ad finem. Librum Akilani Abatí. Cathedralis Acclesiae Legionensis in Hispania codex signatus. Nr. VIII, Madrid, 2011. 
Il existe également des traces de récits de sa vie dans de nombreuses bibliothèques du Moyen Âge ${ }^{10}$. Nous savons que parmi les œuvres les plus lues et copiées figurait la Vita de saint Martin écrite par Sulpice Sévère ${ }^{11}$. C'est le cas à Samos ${ }^{12}$, Oviedo ${ }^{13}$, ou Guimarães durant le $\mathrm{X}^{\mathrm{e}}$ siècle $^{14}$. La bibliothèque du monastère d'Oña, de la province de Burgos, fondée en 1011 possédait une Vita sancti Martini ${ }^{15}$, et on connaît également un autre exemplaire du XII ${ }^{\mathrm{e}}$ et du XIII ${ }^{\mathrm{e}}$ siècle ${ }^{16}$. Le document relatif à une dote transmise par doña Adosinda, le 14 mai 1019 à l'église galicienne de Saint-Martin de Lalín, n'est pas non plus dépourvu d'intérêt. Parmi le riche trousseau liturgique figure le Liber beati Martini ${ }^{17}$. Par ailleurs, dans un Legendario de la Bibliothèque du Collège Royal de saint Isidore de León, daté de la fin du $\mathrm{XII}^{\mathrm{e}}$ siècle, où la littérature hagiographique détient une place importante, on trouve le "Martinellus " en entier, avec les mentions de saint Brice et d'autres saints français ${ }^{18}$.

10. DíAz y DíAz, Manuel C., Códices visigóticos de la monarquía leonesa, León, 1983, p. 244.

11. SulPICE SÉvÈrE, Vie de Saint-Martin, FonTAINE, Jacques (éd.), Sources chrétiennes 133, 3 vols., Paris, 1967; VITA y VAESEn, Jean, "Sulpice Sévère et la fin des temps ", The use and abuse of eschatology in the Midde Ages, VERBEKE, Werner, VERHELST, Daniel et WelKENHUYSEN, Andries, (éd.), Leuven, 1988, p. 49-71. Concernant la rédaction des autres Vitae, voir : FERnÁndez GonzÁlEz, Etelvina, "San Martín de Tours en el camino de Santiago... ", notes 3 à 6 .

12. DíAz y Díaz, Manuel C., Códices visigóticos..., p. 197-198, note 132.

13. La basilique de San Salvador d'Oviedo reçut d'Alphonse III et de sa femme Chimène, le 10 août 908 , une série de volumes parmi lesquels figurait la vie du saint écrit par Sulpice Sévère; voir : Díaz y Díaz, Manuel C., Códices visigóticos..., p. 160. Il est probable que ce soit cette œuvre que mentionne Antonio de Morales dans la description des livres de la bibliothèque d'Oviedo dans Orden del Rey Don Phelipe II a los reynos de León, Galicia y Principado de Asturias, réed. Oviedo, 1977, p. 97.

14. Elle est connue grâce à l'acte fondateur de Mummadonna Díaz, du 26 janvier 959, relatif au monastère de Guimarães qu'elle avait fondé; elle donna de nombreux biens de toute nature comme des livres. Dans la liste de ceux-ci figurait une Vita beati Martini episcop. Voir : Díaz y Díaz, Manuel C., Códices visigóticos..., p. 216. Du même siècle est conservée une autre Vita sancti Martini de Sulpice Sévère dans un manuscrit factice de l'Académie Royale d'Histoire de Madrid (RAH, Madrid), cód. 13, f f $^{\circ} \mathrm{v}^{\circ}$ a $79 \mathrm{r}^{\circ} \mathrm{b}$; voir : Ruiz García, Elisa, Catálogo de la sección de códices de la Real Academia de la Historia, Madrid, 1997, p. 121-124, en particulier, p. 122.

15. Il semble qu'il existe un catalogue de sa bibliothèque inséré dans le manuscrit de la Bibliothèque Royale de San Lorenzo del Escorial, R. II. 7, fol. 147; voir : DíAz y DíAz, Manuel C., Códices visigóticos..., p. 242.

16. Au même siècle, le manuscrit daté de l'Académie Royale d'Histoire (RAH Madrid), cód. 17, contient également la Vita santi Martini de Sulpice Sévère, $\mathrm{f}^{\circ} 1 \mathrm{r}^{\circ}$ à $27 \mathrm{r}^{\circ}$ et RuIz GARCíA, Elisa, op. cit., p. 285-288, notamment, p. 285; p. 106, l'auteur y catalogue un manuscrit factice qui inclut la référence d'une Vita aux fols. 95 v b à 104 r b : Madrid, Académie Royale d'Histoire (RAH Madrid), cód. 10.

17. Díaz y Díaz, Manuel C., Códices visigóticos..., p. 198 et note 132. Ce chercheur pense que ce codex serait le texte de Sulpice Sévère sur la vie de saint Martin de Tours. voir : Chao CASTRo, David, "La iglesia medieval de San Martiño de Lalín ", Descubrindo. Anuario de Estudios e Investigación DEZA, 4, 2002, p. 127-150, et plus particulièrement, p. 137, note 36 .

18. SuÁrez González, Ana Isabel, Patrimonio cultural de san Isidoro de León. Serie Bibiográfica. III Los Códices VI-X.2, León, 2001, p. 137-233, notamment, p. 141. 
Mais revenons à la Vita de saint Martin de Tours. Le récit de cette dernière servit, semble-t-il, de modèle à la rédaction de la Vita Aemiliani, un saint hispanique, soit par copie directe soit ces récits provinrent d'une source commune ${ }^{19}$. Dans cette Vita, le saint de la Rioja est comparé au parangon tourangeau auquel il est fait référence en ces termes : "Oh, nouveau saint Martin, qui vêtit le Christ des habits du pauvre ${ }^{20}$ ! "Il fit preuve de charité envers les pauvres car "il coupa les manches de sa tunique et les offrit, avec une immense bonté, ainsi que la cape qu'il portait ${ }^{21}$ ". Il est également fait allusion aux nombreux miracles qu'il réalisa comme ceux du saint tourangeau ${ }^{22}$. De plus, on remarque que l'on recourt à saint Martin en de multiples occasions. Ainsi, dans le Pénitentiel de saint Dominique de Silos du XI ${ }^{\mathrm{e}}$ siècle, il est précisé qu'il fallait invoquer saint Martin pour conjurer le mauvais sort ${ }^{23}$.

Dans ces brefs récits extraits d'œuvres hispaniques où la figure du saint et la localité de Tours sont présentes, nous ne pouvons pas oublier l'importance donnée au Codex Calixtinus ${ }^{24}$. Dans ce dernier, il est précisé que des quatre chemins de France qui vont à Saint-Jacques-de-Compostelle et

19. C'est ce qu'a étudié Isidro Bango : voir : BANGo ToRviso, Isidro Gonzalo, Emiliano, un santo de la España visigoda y el arca románica de sus reliquias, Salamanque, 2007, p. 35.

20. Voir : Oroz, José, "Sancti Braulionis Caesaravgustani Episcopi. Vita Sancti Aemiliani », Perficit, IX, numeros 119-120, 1978, p. 165-227, en particulier, chap. XX, BANGO ToRvISO, Isidro Gonzalo, op. cit., p. 22.

21. Oroz, José, op. cit., c. XX, p. 203-204.

22. On rappellera, parmi de nombreux miracles, qu'il lutta contre le démon (chap. vII, p. 195), qu'un ange lui annonça sa mort prochaine (chap. Xxv, p. 209-211), qu'il rendit la vue à une femme aveugle grâce à l'huile de sa lampe (chap. xxıx, p. 213). On peut ici évoquer un exemple plastique singulier. Celui d'un retable du $\mathrm{Xv}^{\mathrm{e}}$ siècle de l'église de Requejo (Astorga), aujourd'hui présent dans le Musée des Chemins de cette localité. Sur celui-ci est représentée l'apparition qu'eut le saint du Christ après avoir partagé avec Lui la Cape. Le tissu fut substitué, dans cette scène, par une riche dalmatique sur le lit où repose Martin. Il lui manque la manche gauche, ce qui peut être interprété comme le morceau d'habit qu'il avait donné au Christ aux portes d'Amiens. Voir : RIvERA, José, "Anónimo. Siglo Xv. Las pinturas de la Vida de San Martín de Tours ", Las Edades del Hombre. El arte en la Iglesia de Castilla y León, ficha catalográfica nº 108, Salamanque, 1988, p. 194-195. Pourrait-on interpréter cet épisode de la manche comme une influence du récit de la Vita Aemiliani ? Cependant, même si nous ne souhaitons pas nous attarder sur ce sujet, nous observons l'existence d'épisodes similaires dans les deux vies, et qui se rapprochent également des passages hagiographiques d'autres Vitae. On pourra citer comme exemple les guérisons miraculeuses, les rêves qu'ils ont eus, ou encore les apparitions angéliques, les affrontements avec le diable ou les créations scénographiques qui apparurent lors de leur ascension au ciel. Ce dernier aspect apparaît inséparable de la plastique du Moyen Âge, et plus particulièrement durant l'ère romane. Voir : FERNÁNDEZ GONZÁLEZ, Etelvina, "San Martín de Tours en el camino de Santiago... ", p. 24-29 et BANGo ToRviso, Isidro Gonzalo, Emiliano..., p. 84, 126, 127, 132, 133, 134, 136 et 138.

23. Ces textes appartiennent au Pénitenciel : Quintum deinde biduanum quod tenditur usque ad letanias sancti Martini y Sextum triduanum quod depositione sancti Martini usque ad natalem domini continetur. Voir : Bezler, F. (éd.), Paenitentiale Silense, cap. XIII, De temporibus ieivniorvm generalivm, dans Paenitentialia Hispaniae, Turnhout, 1998, p. 41.

24. Liber Sancti Jacobi. Codex Calixtinus, MoraleJo, Abelardo, Torres, Casimiro, et Feo, Julio. (trad.), Santiago de Compostela, 1951. 
se réunissent en une seule route à Puente la Reina en terres espagnoles, l'un de ces chemins passe par Tours ${ }^{25}$. La figure du saint est si digne et ses reliques si prestigieuses que l'auteur du texte les incorpore au sein d'un grand récit où il n'omet aucun détail artistique :

"Sur ce chemin, il faut également rendre visite, près des berges de la Loire, au digne corps de saint Martin, évêque et confesseur. Car on le considère comme le magnifique saint qui a ressuscité trois morts, et l'on raconte qu'il a guéri des lépreux et d'étranges énergumènes : des lunatiques, des démoniaques et toutes sortes de fous. Et son sarcophage, où repose près de la ville de Tours sa sacro-sainte dépouille, est couvert d'or et de pierres précieuses qui brillent lors de fréquents miracles. Et il s'érige au-dessus de lui, admirablement construite en son honneur, une vénérable église similaire à celle de Saint-Jacques où accourent les malades qui sont guéris, où les démoniaques sont libérés, où les aveugles retrouvent la vue, où les infirmes remarchent, où de nombreuses maladies sont soignées et où toute demande est traitée convenablement et reçoit l'aide qui lui est due. Ainsi sa glorieuse aura se diffuse partout grâce à ses dignes exploits pour la Gloire du Christ. Sa fête est célébrée le 11 novembre ${ }^{26}$."

Par ailleurs, dans un autre extrait où sont mêlés les miracles de saint Martin avec ceux de saint Jacques, il est comparé au Christ avec les mots suivants : "Saint Martin, qui vit encore, et Notre Seigneur Jésus Christ, ressuscitèrent trois morts ${ }^{27}$. "Ses restes font partie de ceux des corps saints, et ils ne peuvent être déplacés sous aucun prétexte afin que personne ne puisse les emporter " frauduleusement en dehors de la patrie. [...] Il n'y a que quatre saints dont les corps ne peuvent être déplacés de leur sarcophage : saint Jacques de Zébédée, saint Martin de Tours, saint Léonard de Limoges et saint Gilles, le confesseur du Christ ${ }^{28}$ ". Cette force et ce pouvoir divin qui émanent des reliques, liés à l'endroit où elles sont gardées, sont significatifs. Dans un récit sur le déplacement et le contenu des reliques du coffre saint d'Oviedo, à la fin du XII ${ }^{\mathrm{e}}$ siècle ou au début du XIII ${ }^{\mathrm{e}}$ siècle est relaté un miracle ${ }^{29}$, sur lequel nous reviendrons plus tard.

Comme nous pouvons le voir, les liens entre saint Jacques et saint Martin sont nombreux, bien qu'ils ne renvoient pas toujours à des événements glorieux, bien au contraire. Ainsi, les gardiens de la basilique de Saint-Jacques-de-Compostelle et de Tours volaient les offrandes et les cierges. Certains se mêlaient aux taverniers et abusaient des pèlerins ${ }^{30}$. Le texte Calixtinien affirme ensuite :

25. Ibidem, lib. v, chap. I, p. 497.

26. Ibid., lib. v, chap. VIII, p. 538-539.

27. Ibid., lib. II, chap. III, p. 343.

28. Ibid., lib. v, chap. vIII, p. 531

29. A propos des récits de miracles, voir : FERNÁNDEZ GonZÁLEZ, Etelvina, " La Imago Regis y de la jerarquía eclesiástica a través de las artes plásticas (siglos IX-XII) ", Monarquía y sociedad en el Reino de León. De Alfonso III a Alfonso VII, (Fuentes y Estudios de Historia Leonesa), n 118, León, 2007, t. II, p. 45-96, en particulier, p. 73-75.

30. Liber Sancti Jacobi..., lib. I, chap. XVII, p. 214-221. 
" Et que dire de ces faux marchands : Oh quelle avarice et quelle malhonnêteté! Certains réussissaient à former leurs esclaves à ces pratiques en les envoyant au Puy, à Saint Gilles, à Tours, à Plaisance, à Lucques, à Rome, à Bari et à Barletta, car dans ces villes il y avait souvent des écoles pour toutes ces espiègleries [...]. Si vous n'êtes pas lavés de vos innombrables tromperies auprès des Saints en personne, à savoir Saint Jacques, Pierre, Gilles, Léonard, la mère de Dieu Sainte Marie du Puy; Sainte Madeleine, Saint Martin de Tours [...] vous les aurez comme accusateurs devant le seigneur car vous aurez abusé leurs pèlerins ${ }^{31} \ldots$ ".

Dans la basilique de Saint-Jacques-de-Compostelle un autel est dédié au saint tourangeau et à proximité, un monastère lui est consacré, celui de saint Martin Pinario ${ }^{32}$. Tout au long du Moyen Âge, sa figure a toujours été très présente dans l'esprit des fidèles; et il n'est d'ailleurs pas surprenant qu'il soit l'un des principaux protagonistes d'autres œuvres littéraires, comme par exemple en Gaule, où la renommée que saint Martin atteignit dans l'épopée des XIV et $\mathrm{XV}^{\mathrm{e}}$ siècles fut très importante. On pourra citer à ce sujet la célèbre œuvre de Jean de Wauquelin, Histoire de la Belle Hélène ${ }^{33}$.

De la même manière dans le domaine hispanique, les actions généreuses de saint Martin et la charité qu'il pratiqua tout au long de sa vie furent des thèmes récurrents et propices à être intégrés aux recueils d'Exempla comme l'Enxiemplo del ave de Sant Martin du Libro de los Gatos ${ }^{34}$.

\section{Pages-tapis à labyrinthe}

À la fin du x ${ }^{\mathrm{e}}$ siècle, on retrouve une allusion à saint Martin dans le codex Vigilanus. Ce dernier est un magnifique manuscrit de miscellanées réalisé en l'an 976 dans le monastère d'Albelda. À la page dix-neuf, au recto et au verso, ont été disposées des pages-tapis à labyrinthe ${ }^{35}$. Ce sont des compositions avec un caractère ornemental très marqué, où le texte passe presque inaperçu pour le lecteur qui dirige son attention vers l'effet plastique de ces dernières. Cependant, par leur contenu, ces pages ont une signification qui va au-delà d'une simple fonction ornementale.

Tel un labyrinthe occupant la totalité de la superficie encadrée par la bordure, des dessins géométriques génèrent de petits espaces libres où

31. Ibidem, lib. I, chap. XVII, p. 223.

32. Pour une analyse détaillée sur le développement du culte et l'invocation de saint Martin dans le contexte hispanique, voir : FERnÁndEz GonzÁlez, Etelvina, "San Martín de Tours en el camino de Santiago..." ".

33. Sur ce sujet et sur cette figure honorée à la Cour de Bourgogne, voir : JEHAN Wauquelin, La Belle Hélène de Constantinople, DE CRECY, Marie-Claude (éd.), Genève, 2002 et Roussel, Claude, La Belle Hélène de Constantinople. Chanson de Geste du XIV siècle, Genève, 1995, p. 58 et 241-255.

34. Voir : KelLER, John, Esten (éd.), El Libro de los Gatos, Madrid, 1958, p. 37-38.

35. Voir : FERnÁNDEZ GonZÁlez, Etelvina, y GALVÁn FrEILE, Fernando, "Iconografía, ornamentación y valor simbólico de la imagen ", Códice Albeldense 976. Original conservado en la Biblioteca del Real Monasterio de San Lorenzo de El Escorial (d. I. 2), étude qui accompagne l'édition fac-similée, Madrid, 2002, p. 205-277, notamment, p. 235-237. 
sont intercalées des initiales en majuscule qui forment ainsi une légende. Dans le premier, on peut lire : OB HONOREM SANCTI MARTINI et dans le second : MAURELLI ABBATIS LIBRUM. Ils font référence au monastère de saint Martin d'Albelda et à son abbé. La première des compositions est organisée spatialement par de petits carrés qui hébergent des lettres entourées d'éléments géométriques hexagonaux ${ }^{36}$, assemblés les uns aux autres pour constituer un fil unificateur qui recouvre harmonieusement toute la surface. Ils sont colorés alternativement de jaune et de bleu et sont délimités par des traits rouges et noirs qui leur confèrent un aspect volumétrique très marqué. Chacune des figures hexagonales est complétée par des petits cercles colorés dans lesquels l'alternance chromatique augmente la plasticité de la miniature. Il s'agit d'une disposition géométrique complexe élaborée avec beaucoup de soin et d'application. L'autre face de la page est d'apparence similaire ${ }^{37}$.

À la page $18 \mathrm{v}^{\circ}$, la croix aniconique est abritée sous une $\operatorname{arcade}^{38}$, et précède le codex. Nous observons cependant que l'organisation du modèle de ces trois pages a été mûrement réfléchie, parfaitement hiérarchisée, comme il convient à un livre de ce caractère; le livre proprement dit s'ouvre avec la Croix puis vient l'incantation faite à saint Martin qui avait consacré le monastère et son abbé. À la page $20 \mathrm{r}$. commence la Collection Canonique ${ }^{39}$.

Il est important de rappeler que les premières pages contiennent une série de textes variés. Cinq de ces pages sont couvertes, parmi d'autres de carmina figurata ${ }^{40}$. Par cette dénomination, nous nous référons à une série de textes qui, dans leur rédaction, forment des figures et peuvent être lues dans plusieurs sens ${ }^{41}$ (palindromes). Leur caractère ornemental se dégage nettement tout d'abord dans leur contenu bien que celui-ci, à de nombreux moments, et vu la complexité de sa disposition, soit difficile à percevoir ${ }^{42}$.

36. Ces motifs, disposés de manière similaire et utilisés principalement en pavés, sont très présents dans le monde romain dans les mosaïques de la Maison du Paon, à El Jem, et encadrés à l'époque des Sévères : voir : PARRISH, David, Season Mosaics of roman north Africa, s.l., 1984, planche 47 ou dans la Casa dos Repuxos de Conímbriga : voir : Corpus dos mosaicos romanos de Portugal. Conventus Scallabitanus. I. Conímbriga. Casa dos Repuxos. Índice das Estampas, Conímbriga, 1992, planche 33.

37. Fernández GonZÁlez, Etelvina, y Galván Freile, Fernando, «Iconografía... », p. 232-237.

38. Ibidem, p. 232-237.

39. Ibid., p. $237-270$.

40. $\mathrm{F}^{\circ} 1 \mathrm{v}^{\circ}-3 \mathrm{v}^{\circ}$.

41. Fernández GonZÁlez, Etelvina, y GaLvÁn FREILE, Fernando, « Iconografía... ”, p. 209-215.

42. Les textes qui nous occupent ici sont transcrits dans DíAZ y DíAz, Manuel C., Libros y librerías en la Rioja Altomedieval, Logroño, 1991, p. 351-370; du même auteur, voir également : "Vigilán y Sarracino : sobre composiciones figurativas en la Rioja del siglo X ", Lateinische Dichtungen des X. und XI Jahrunderts. Festgabe für Walter Bulst, Heidelberg, 1979, p. 60-92 et ERNEST, Ulrich, Carmen Figuratum. Geschichte des Figurengedichts von den antiken Ursprüngen bis zum Ausgang des Mittelalters, Köln, 1991, p. 474-491. 
Il faut chercher leur origine dans la poésie alexandrine où de tels poèmes de figures (technopaignia) ${ }^{43}$ inspirèrent les textes des poètes du IV siècle comme Porphyrius Optatianus, en l'honneur de Constantin le Grand, et Ausone ${ }^{44}$. Nous analysons par la suite ces modèles car, à l'époque médiévale, ces formes littéraires de tradition antique et byzantine parvinrent en Europe occidentale. Elles furent utilisées entre le $\mathrm{V}^{\mathrm{e}}$ et le $\mathrm{IX}^{\mathrm{e}}$ siècle par de grandes personnalités de la littérature, tels Venance Fortunat ${ }^{45}$, Alcuin d'York, qui fut abbé de Tours ${ }^{46}$, ou Raban Maur, qui se forma dans cette ville gauloise. Parmi les écrits de ce dernier, on citera le Liber de Laudibus Sanctae Crucis (806) ${ }^{47}$, où apparaissent ces compositions métriques qui, combinées à la mise en couleur de certaines parties, acquièrent un caractère figuré ${ }^{48}$. Comme nous pouvons le voir, il existe de nombreux exemples qui nous permettent de souligner les forts liens qui existent tout au long du $\mathrm{X}^{\mathrm{e}}$ siècle entre le monastère de la Rioja et l'atmosphère et la culture tourangelles ${ }^{49}$.

On peut dès lors se demander où voulaient en venir les moines de SaintMartin d'Albelda en incluant dans le codex que nous venons de citer cette page labyrinthe avec l'allusion au saint patron. Peut-être cherchaient-ils à obtenir la générosité des souverains du royaume de Pampelune-Najera dont le portrait est présent dans le manuscrit $\left(f^{\circ} 428\right){ }^{50}$. Rappelons que le Vigilanus est un livre d'apparat, de propagande, qui met en valeur et montre

43. Simmias de Rhodes, vers 300 av J.-C., est l'un des grands auteurs de ce genre littéraire. Sur la littérature de cette époque, nous renvoyons à PowELL, I. U., Collectanea Alexandrina. Reliquiae minores Poetarum Graecorum Aetatis Ptolemaicae. 323-146 a.C., Oxonii, 1925, d'après : Fernández GonzÁlez, Etelvina y Galván Freile, Fernando, "Iconografía... ", note 31 .

44. CuRTius, Ernst Robert, La Littérature européenne et le Moyen Age latin, Paris 1956, p. 443, et FernáNDEZ GonZÁlEZ, Etelvina y GALVÁN FrEILE, Fernando, "Iconografía... », p. 209.

45. Cet auteur écrivit des poèmes dédiés à la Croix du Christ, et dans lesquels figurent deux hymnes avec des formes dans leur organisation, que l'on pourrait nommer carmina figurata ; voir : BRunHöLz, Franz, Histoire de la littérature latine du Moyen Âge, t. I, $1^{\circ}$, Turnhout, 1991, p. 117 sqq; FERnÁNDEZ GonZÁlEZ, Etelvina et GALVÁn FrEILE, Fernando, "Iconografía... ", p. 209 et ERNEST, Ulrich, op. cit., p. 474-491.

46. Dans son Poème à la Croix, il utilise également la formule des carmina figurata. BRunhölz, Frank, Ibidem, $2^{\circ}$, p. 29 sqq et Monumenta Germaniae Historica, Poetae Latini, DüMmLER, Ernest. (éd.), t. I, 1881, p. 160-351 et FERNÁNDEZ GonZÁlez, Etelvina, y Galván FrEILE, Fernando., "Iconografía... ", p. 209.

47. Patrologia Latina, t. CVII, cols. 133-294 et dans Monumenta Germaniae Historica Poetae Latini, t. II, p. 186, $\mathrm{n}^{\circ} 21,11$.

48. Prochno, Joachim, Das Schreiber-und das Dedikationsbild in der Deutschen Buchmalerei, 1929, p. 11 et sq. ; CURTIUS, Ernest. Robert, op. cit., p. 441 et sq. ; BRUNHÖLZ, Frank, op. cit., $2^{\circ}$, p. 85 et ss.; VACANT, Alfred, MangEnOT, Eugène et Amann, Émile, Dictionnaire de Théologie Catholique, XIII, 2, Paris, 1937, col. 1617 et BoINET, Amédée, " Notice sur deux manuscrits carolingiens à miniatures exécutés à l'Abbaye de Fulda ", Bibliothèque de l'École des Chartes, LXV, 1904, p. 355-363.

49. Pour une analyse précise, se rapporter à FERnÁndEz GonZÁlez, Etelvina, " San Martín de Tours en el camino de Santiago... ", p. 227-228.

50. Ces monarques étaient Sanche II, la reine Urraca et Ramiro, frère du souverain et Seigneur de Viguera, et ce furent sur ces terres qu'on érigea le monastère. Voir : FERNÁNDEZ GonZÁLEZ, Etelvina, y GALVÁN FrEILE, Fernando, " Iconografía... ", p. 270-274. 
le monarque. Il est dès lors possible que les moines aient cherché à obtenir sa magnanimité et sa charité envers le monastère, de la même manière que saint Martin l'avait fait avec le pauvre.

\section{Images figurées}

La figure du saint Tourangeau et ses bonnes actions furent toujours un exemplum à imiter et les œuvres artistiques un des moyens de sa diffusion. Avec l'arrivée du style roman, de la sculpture monumentale, de l'imagerie et d'autres représentations plastiques, se sont multipliés les images, les scènes et les programmes iconographiques liés à saint Martin. Tous les endroits furent bons pour les mettre en scène ${ }^{51}$ et ce fut le cas tout au long du Moyen Âge.

Mais où eurent lieu ces événements liés à saint Martin? La majorité d'entre eux se déroulèrent dans l'église ou dans les espaces liés aux dépendances abbatiales. Les récits de la Vita en parlent. Dans la période qui nous intéresse, jusqu'au début du XIII ${ }^{\mathrm{e}}$ siècle, on peut voir que la conception de l'espace architectural, quel qu'il soit, s'entend fondamentalement d'un point de vue symbolique. Nous nous occuperons de cela par la suite, en choisissant des exemples artistiques fort expressifs. En tout cas, nous avons constaté que, dans le domaine hispanique, la représentation des différents épisodes de sa vie, au vu des éléments qui sont parvenus jusqu'à nos jours, est sobre et tardive.

La représentation la plus simple que nous allons étudier maintenant correspond au tympan de l'église paroissiale de Pontevedra de Saint-Martin de Moaña.

Abritée sous des arcatures, on y découvre la figure de saint Martin au centre de la composition, entourée par celles de saint Brice et saint Émilien ${ }^{52}$. Dans ce cas, bien qu'il s'agisse d'éléments architecturaux, les arcatures servent uniquement à mettre en valeur les personnages qui sont encadrés par les bordures, et témoignent ainsi, comme il se devait, de la dignité épiscopale.

Comme nous réalisons ici un bref inventaire, nous nous intéresserons également aux frontons catalans de Puigbó ${ }^{53}$, Gía ${ }^{54}$ et d'autres encore qui sont conservés dans le musée des pèlerinages de Saint-Jacques-de-

51. Ibidem, p. 228-238.

52. L'inscription qui entoure les personnages donne leurs noms : SCI : EMILIANI : SCS : MARTINVS : EPS : SCI : BRICII : EPI : ARAS : FECI; voir : BANGO TORVISO, Isidro, Arquitectura románica en Pontevedra, La Coruña, 1979, p. 186-187. Une formule similaire a été utilisée sur le frontispice de l'église asturienne de saint Martin d'Argüelles (Siero). Sur le petit relief, il n’y a de la place que pour le saint gaulois. Voir : FERnÁNDEZ GonZÁLEZ, Etelvina, "San Martín de Tours en el camino de Santiago... ", p. 228, 229, 230 et fig. 2.

53. Ce frontispice est présent dans le Musée Episcopal de Vic, voir : Gros I PujoL, Miquel dels Sants, Museu Episcopal de Vic. Romànic, Sabadell, 1991, p. 40.

54. García Guatas, Manuel, " Frontal de altar de la iglesia de san Martín de Chías ", Signos. Arte y Cultura en Alto Aragón medieval, Zaragoza, 1993, p. 354-355 et CAMPS I SòRIA, Jordi, 
Compostelle, originaires probablement de la Ribagorce ${ }^{55}$. Ces derniers représentent différents épisodes de la Vita de saint Martin. Aucun ne fait clairement allusion à un événement précis, mais les passages peints ne laissent pas le moindre doute sur le lieu où se sont produits les faits ${ }^{56}$. Sur la pièce de Compostelle, on peut contempler sa figure après sa consécration comme évêque. Saint Martin est assis sur le trône et flanqué de deux acolytes $^{57}$, il est vêtu des habits liturgiques et des insignes de sa charge ${ }^{58}$. Il en va de même avec l'illustration du passage de la Messe. Ce passage pour des raisons évidentes, est connu comme la Messe ou la seconde Charité du saint ${ }^{59}$. Le miracle peut également faire figure d'exemple sur le fronton de Gía, où l'on célèbre l'Eucharistie à coté d'un autel finement reproduit ${ }^{60}$. Deux personnages l'accompagnent, vêtus de tuniques blanches aux manches longues qui cachent leurs mains. Le prodigieux miracle est exécuté par la Main de Dieu qui sort des nuages; cependant il n'y a aucune référence claire à un autre élément du récit, et il n'y a pas non plus d'allusion visible à l'espace architectural ${ }^{61}$.

"Frontal de Gía ", Prefiguración del Museu Nacional d’ Art de Catalunya, Barcelona, 1993, p. 193-195.

55. Voir : Post, Chandler Rathfon, A History of Spain Painting, V. App., Adicción vols. HV, (reed. New York, 1970), p. 243-247 et Romei e Iubilei. Il pellerinaggio medievale a san Pietro (350-1350), Rome, 2000, p. 366 et Fernández GonZález, Etelvina, "San Martín de Tours en el camino de Santiago... ", p. 233-238 et fig. 6.

56. Concernant celui de Puigbó, le plus ancien des trois, le fond a été découpé en cinq compartiments où les couleurs sont alternées : rouge, bleu et crème. Dans celui de Gía, le fond continu montre le revêtement couvert d'étain et de vermeil, voir : CARBONELL I Esteller, Eduard, "Las artes del románico » dans CARBONELl I EsTELLER, Eduard, et SuREDA I Pons, Joan, Tesoros Medievales del Museu Nacional d'Art de Catalunya, Barcelona. 1997, p. 13-368, principalement, p. 188-189. La pièce de Saint-Jacques-de-Compostelle est recouverte de feuille d'or.

57. Concernant la couronne qui le touche, voir : FERnÁndez GonZÁlez, Etelvina, "San Martín de Tours en el camino de Santiago... ", p. 236 et note p. 165.

58. Assis sur le trône et avec les attributs épiscopaux, il est présent dans le compartiment central du retable de Gía. FERnÁnDEZ GonZÁLEZ, Etelvina, « San Martín de Tours en el camino de Santiago... ». p. 234.

59. La première Charité fait référence au geste d'Amiens et la seconde relate les épisodes de Tours. Les deux habits, à savoir le morceau de la cape et la tunique, sont devenus des reliques. Venance Fortunat, à partir des peintures de la basilique de la ville de la Loire, réalisa deux épigrammes qui leurs sont dédiées : Chlamys divisa et Tunicam dedit, Carmina, 1. X, n. VI, vs. 103-116, p. 137. Voir : MEYER, Wilhelm, Der Gelegenheitsdichter Venantius Fortunatus, Abhandlungen der kön. Akad d. Wissensch. zu Göttingen, phil.-hist. Klasse, nouv. série, t. IV, Berlin 1901, p. 68. Voir : SAuvEL, Tony, "Les miracles de SaintMartin. Recherches sur les peintures murales de Tours aux $\mathrm{v}^{\mathrm{e}}$ et $\mathrm{VI}^{\mathrm{e}}$ siècles ", Bulletin Monumental, 104, 1956, p. 153-179 et DelEHAYE, Hippolyte, "Une inscription de Fortunat ", Mélanges d'hagiographie grecque et latine, 1966, p. 204-211. Voir également : FERNÁNDEZ GonZÁlEZ, Etelvina, "San Martín de Tours en el camino de Santiago... " p. 235-236.

60. Ces deux faits caritatifs étaient parfaitement différenciables dans les peintures de la basilique tourangelle rénovée par Grégoire de Tours; voir : Historia Francorum, 1, X, cap. XXXI, dans Scriptores Rerum Merovingicarum, t. I, p. 448.

61. Les ressemblances avec la scène de la Messe de saint Grégoire sont évidentes. Voir : MARTENS, Didier, «Rayonnement d'un modèle. Emprunts méconnus à la messe de saint 
Sur le fronton du musée de Saint-Jacques, on distingue une scène où le saint célèbre la liturgie. Il lève les mains très haut en signe de prière. Il est entouré de deux clercs qui lui portent la crosse et la mitre. Aucun autre élément ne fait référence à la vision de la seconde Charité ${ }^{62}$.

Au-delà des éléments précédemment abordés, ont été incorporés d'autres épisodes intéressants qui concernent la maladie et la mort du saint. Dans les deux cas, nous savons que ces événements se produisirent à Candes. La première scène est représentée sur les frontons de Saint-Jacques et Gía. Les deux compositions sont identiques. Elles représentent Martin, sur son lit de mort au moment où le démon apparaît pour le tenter ${ }^{63}$. Dans l'œuvre galicienne, un ange surgit des cieux pour le réconforter dans ses derniers instants. Dans la scène de la seconde pièce, il est accompagné par un moine et un acolyte. Dans la partie du haut, une lampe à été dessinée afin d'éclairer la scène ${ }^{64}$.

L'évêque mort, sur son lit, est présent sur le antipendium de Puigbó et dans le musée de Saint-Jacques. Dans la scène du premier fronton, le saint est accompagné par un ange et deux clercs avec la croix, le livre et l'encensoir. Le texte mentionne : "Pour avoir été si généreux avec le pauvre sur la terre, Martin vit le ciel ${ }^{65}$. " Dans l'autre composition, la formule est la même; cependant le nombre de personnages est plus important et des fidèles qui pleurent sa perte sont présents.

Comme nous l'avons vu dans ces exemples, les fonds sont neutres et le concept d'abstraction de l'espace et du temps est évident. Le message des images est suffisamment explicite pour suggérer au spectateur le contexte abbatial dans lequel se sont déroulés ces événements.

La représentation figurée la plus intéressante est sans aucun doute la miniature qui illustre un fragment du Cartulaire appartenant à une confrérie de religieux et de laïcs ${ }^{66}$, fondée en l'honneur de saint Martin du Canigou le

Grégoire flémallienne dans la peinture et la tapisserie bruxelloises ", Annales d'histoire de l'art et d'archéologie, XXIIII, 2001, p. 21-59.

62. Nous pensons qu'il s'agit d'une simple représentation de saint Martin célébrant l'Eucharistie, en accord avec les compositions du milieu du xIII ${ }^{\mathrm{e}}$ siècle. Pour une réflexion plus approfondie sur cette scène, nous vous renvoyons à : FERNÁNDEZ GONZÁLEZ, Etelvina, "San Martín de Tours en el camino de Santiago... ", p. 236 et note 165.

63. Les deux couleurs symboliques des figures diaboliques nous interpellent : vert et rouge pour le frontispice de Galice, et noir pour le second. Voir : FERNÁNDEZ GonZÁLEZ, Etelvina, "San Martín de Tours... ». p. 236-337 et note 168, et ID. "A propósito del mal : posesiones y exorcismos en la plástica del medievo ", L'espai del mal, Lleida, 2005, p. 117142.

64. Dans sa cellule, espace monacal, Martin reçut de nombreuses visites célestes. Voir : FERNÁNDEZ GonZÁlEZ, Etelvina, "San Martín de Tours... ", p. 235 et note 155.

65. Ibidem, p. 237-238.

66. Sur le sujet des confréries au Moyen Âge, nous renvoyons à l'étude documentée de Gregoria. Cavero qui présente une bibliographie fournie sur ce sujet. Voir : CAVERO Domínguez, Gregoria, "Las cofradías impulsoras de la devoción popular ", Memoriae Ecclesiae, XXI, Zaragoza-Oviedo, 2002, p. 9-95. 
jour de Pâques $1195^{67}$ (fig. 1). Cette riche composition, que l'on peut dater de 1200 , a été étudiée précisément par Patricia Stirnemann ${ }^{68}$. Comme il était d'usage dans les documents médiévaux, l'illustration sert de préambule au récit textuel où est stipulé le rôle de la confrérie. Sa mission consistait à maintenir allumée, de jour comme de nuit, une lampe à huile devant l'autel du monastère, à illuminer l'ensemble de l'église le jour de la fête de saint Martin, à célébrer la messe hebdomadaire pour l'âme des frères vivants ou défunts et enfin, à célébrer une trentaine de messe après la mort d'un membre de la confrérie et leur enterrement dans le cimetière du monastère. Par ailleurs, après avoir réalisé les dépenses mentionnées, il devait, si la somme prélevée était suffisamment importante, garder le supplément afin de l'utiliser pour les besoins de l'église ${ }^{69}$.

La miniature se déploie en deux tableaux superposés ${ }^{70}$. Le tableau supérieur est présidé par la Maiestas dans le cercle de l'éternité, duquel surgissent quatre tiges en forme de croix. Autour d'elles, sont disposées les figures symboliques des évangélistes. La composition est entourée par des images de Marie à la droite du Christ et de saint Martin à sa gauche, comme en témoigne les deux tituli. D'un point de vue plastique, les réminiscences des ateliers byzantins de la Sicile normande sont évidentes. Le style des images et le graphisme du dessin rappellent la pierre tombale de l'archevêque Richard Palmer de Messine (1195) ${ }^{71}$.

La frise inférieure représente une scène qui se déroule à l'intérieur d'un temple où l'on distingue parfaitement la nef, le presbytère et une tour adossée à l'extérieur du frontispice. Dans la chapelle, un clerc célèbre la liturgie et les fidèles assistent à la messe depuis la nef. Si l'on tient compte du fait que les programmes iconographiques des cartulaires médiévaux étaient

67. Paris, École des Beaux-Arts, Col. J. Masson, $\mathrm{f}^{\circ} 38$.

68. Voir : StiRnemann, Patricia, "L'illustration du Cartulaire de Saint-Martin du Canigou ", Les Cartulaires. Actes de la Table ronde organisée par l'École nationale des Chartes et le G.D.R. 121 du CNRS, (Paris, 5-7 décembre 1991), Paris, 1993, p. 171-178. Voir également : Blanchard, Louis, "Rôle de la Confrérie de Saint-Martin du Canigou ", Bibliothèque de l'École des Chartes, 42, 1881, p. 5-7; LEROQUAIS, Víctor, "La donation Jean Masson à l'École nationale des Beaux-Arts ", Les trésors des bibliothèques de France, t. II, Paris, 1929, p. 93; DELCOR, Mathias, " Quelques grandes étapes de l'histoire de Saint-Martin du Canigou aux $\mathrm{XI}^{\mathrm{e}}$ et $\mathrm{XII}^{\mathrm{e}}$ siècles (Documents et monuments) ", Les Cahiers de Saint-Michel de Cuxa, t. 12, 1981, p. 49-77, en particulier, p. 63-64 et AINAUD DE LASARTE, Joan, La pintura catalana. La Fascinación del Románico, Barcelone, 1989, p. 27. Cette miniature est également étudiée dans : Fernández GonZÁlez, Etelvina, "San Martín de Tours... », p. 238.

69. Nous reprenons ici la référence STIRnEMANn, Patricia, op. cit., p. 171-172 et note 3.

70. La miniature présente un dessin très soigné. La gamme chromatique est réduite, et se limite à une combinaison de rouge et crème qui rappelle la tonalité du parchemin avec quelques touches de bleu. Sur les bandes colorées des fonds qui ne sont pas l'apanage exclusif de la miniature hispanique à cette période, voir : STIRnEMAnN, Patricia, op. cit., p. 175 et note 10. Du point de vue plastique, on note des traits d'influence byzantine qui se sont généralisés en Occident à partir de 1200 environ.

71. Voir : Di Giacomo, Caterina, "La lastra tombale dell'arcivescovo Riccardo Palmer ", dans : ANDALORO, Maria, Federico e la Sicilia, della terra alla corona, arti figurativi e arti suntuarie, Palerme, 2000, p. 308-311. 
réalisés ex novo, selon la donation spécifique annotée sur chaque codex, tout semble indiquer ici que cette miniature représente l'église de SaintMartin du Canigou et ses confréries présentes lors de l'office religieux ${ }^{72}$ (fig. 2).

Figure 2 - Monastère de Saint-Martin du Canigou

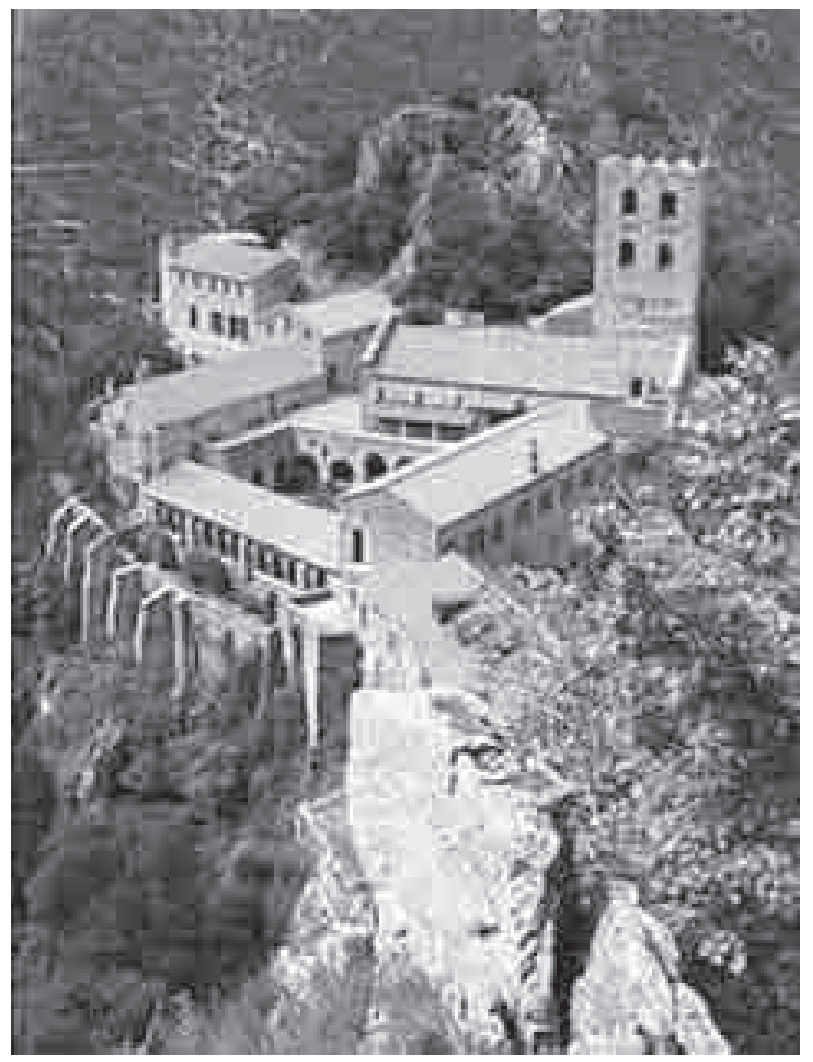

Les éléments qui nous permettent de soutenir une telle hypothèse sont nombreux. Nous mentionnerons en premier lieu la lampe, objet de la création de la confrérie. Cette pièce, très bien taillée est accrochée à la pergola, à l'entrée du presbytère. Elle est composée de deux vases qui sont attachés à différentes hauteurs par trois chaînes. Sous ces dernières, se tient un récipient qui empêche l'huile de se répandre ${ }^{73}$.

72. Nous suivons ici l'opinion de LeRoQuais, Vlíctor et STIRnEMAnN, Patricia, op. cit., p. 175, se prononce également dans ce sens.

73. Sa composition est la même que celle qui illumine la Maiestas à l'extérieur du diptyque, de l'évêque don Gonzalo, de la Sainte Chambre de la cathédrale d'Oviedo et d'autres qui, avec la même fonction, se contemplent sur les peintures de la voûte de 
L'usage des lampes et des lumières est inséparable du temple et les références qui se rattachent aux textes bibliques sont nombreuses ${ }^{74}$. Au sens figuré, Dieu est lampe et lumière (2 Sam. 22, 29). La lampe et la lumière sont les symboles de la vie. Cette lampe que les membres de la confrérie du Canigou devaient maintenir allumée en permanence devant l'autel, constitue le souvenir de la flamme éternelle qui indique la présence du Seigneur. Les lumières permettent de maintenir les fidèles éveillés et vigilants ${ }^{75}$. Le même auteur, par extension, qualifie les figures de la vierge et de saint Martin de lampes; Marie est une lampe pleine d'huile ${ }^{76}$, et le saint tourangeau reçoit le même qualificatif qu'il avait donné au Précurseur : "On dit de Jean qu'il n'était pas la lumière mais une lampe allumée et resplendissante [...]. Car Martin lui aussi fut une lampe allumée et lumineuse ${ }^{77}$. "Sur ce même sujet, nous pouvons également rapporter la citation suivante : " Ne pense pas que les lampes de Martin soient très ornées ou vides. Ce n'est pas une vierge présomptueuse et il a une grande réserve d'huile ${ }^{78}$."

Nous pensons que cette scène correspond au moment solennel de l'offertoire comme en témoignent les objets liturgiques disposés sur l'autel couverts par les nappes ${ }^{79}$. On peut ainsi y voir la croix, le calice ${ }^{80}$ et le pain divisé en quatre parts grâce à une césure en forme de croix ${ }^{81}$. Il était d'usage que les fidèles emportent l'offrande du pain et du vin. Le pain était remis devant l'autel avec les mains couvertes par un linge en signe de respect ${ }^{82}$.

l'abside de l'église aragonaise de Ruesta. Son aspect rappelle les chandeliers de verre de facture islamique et qui sont encore utilisés dans les vieilles mosquées du Caire. Voir : KADI, Wadad, Islamic. History and civilisation, Studies and texts, Leiden, 2001, p. 47-56.

74. Dans le domaine hispanique, depuis des temps très anciens, il fallait maintenir allumées les lampes devant les reliques Cela est stipulé dans le concile de 597. Voir : VivEs, José. (éd.), Concilios visigóticos e Hispano-Romanos, Barcelona-Madrid, 1965, p. 156-157 et BAngo Torviso, Isidro Gonzalo, Emiliano..., p. 138.

75. Cette idée est développée dans le Sermon 3 de la Veillée de la Nativité : " Ainsi donc, bien éveillés et avec les lampes allumées, nous surveillerons toute la nuit nos pensées et nos actions pour que, si le Seigneur naît au début de la nuit, il nous trouve disposé au milieu de la nuit ou à l'aube "; voir : Obras completas de San Bernardo, edicion de los monjes Cistercienses de España, t. III, Madrid, 1985, p. 153.

76. Parmi les nombreuses éloges annotées par saint Bernard, il affirme au sujet de Marie : "même la nuit sa lampe ne s'éteint pas ". Voir : Sermon 3, l'Ascension de Sainte Marie, Obras completas..., t. IV, p. 353.

77. Voir : Sur la fête de l'évêque saint Martin, Obras completas..., t. IV, p. 637.

78. Ibidem, p. 639. Dans le même passage de saint Bernard, il est écrit qu'il soigna avec de l'huile une femme paralytique. Voir également : Epístola a Desiderio, chap. 16, p. 158. Avec l'huile de la lampe du temple de Saint-Emilien il rendit la vue à la jeune Euphrasie. Le miracle est représenté dans l'arcature mentionnée datant du troisième quart du XI ${ }^{\mathrm{e}}$ siècle. Voir : BANGo ToRviso, Isidro Gonzalo, Emiliano..., p. 138-139.

79. Jungmann, José Antonio, El Sacrificio de La Misa. Tratado histórico-litúrgico, Madrid, 1963, p. 549-551 et RigheTti, Mario, Historia de la Liturgia, t. II, Madrid, 1965, p. 261-294.

80. Concernant la croix et le calice, le miniaturiste les a réalisés avec un soin particulier, comme s'il souhaitait montrer qu'il s'agissait de riches pièces.

81. Jungmann, José Antonio, op. cit., p. 579.

82. Cette formule fut habituelle dans le rite byzantin et aussi dans la liturgie hispanique : voir : Jungmann, José Antonio, op. cit., p. 557 et RighetTI, Mario, op. cit., p. II, p. 275. 
L'huile pour les lampes, les cierges et l'encens ${ }^{83}$ furent également considérés comme des offrandes particulières. Après l'offrande, le clergé de cette représentation, qui est en habit liturgique et suit cette vieille cérémonie issue des cercles carolingiens, encense les dons avec un beau turibulum et une attitude très naturaliste ${ }^{84}$.

Parmi les fidèles représentés qui assistent à la scène, la dame en proskinesis et avec les mains couvertes d'un voile retient notre attention. P. Stirnemann considère qu'elle a pu être chargée de fabriquer le pain et de le porter jusqu'à l'autel ${ }^{85}$. L'auteur précédemment mentionné a souligné également l'importance donnée aux deux femmes dont l'attitude est proche de la vierge, car leur présence n'est pas inscrite dans le document de constitution de la confrérie. Cependant, il n'était pas rare de constater leur aide dans des scènes sacrées de ce genre.

Si nous nous centrons sur la posture des hommes de ce groupe, il semble qu'ils soient en train de prier, de déclamer ou de chanter. Nous savons que lors de la liturgie du jour de Pâques, après l'offertoire, on entonnait trois répons en souvenir des trois vierges devant le sépulcre ${ }^{86}$. Ne pourrait-on pas voir ici l'influence mutuelle de ces deux pratiques ${ }^{87}$ ? N'oublions pas que la confrérie de saint Martin du Canigou fut fondée le jour de Pâques de l'année 1195. Si tel a été le cas, nous pourrions donc être en train d'assister à la cérémonie commémorative de la congrégation.

Les deux cloches accrochées au toit à l'intérieur de la nef attirent également notre attention. Il semble évident qu'elles sont liées à la liturgie des défunts, puisqu'elles devaient annoncer la mort des membres de la confrérie, les prières et les cérémonies funèbres ${ }^{88}$. Dans la scène qui nous intéresse, il y a une autre référence qui, dans l'édifice, renforce l'idée que souhaite montrer de façon ostentatoire le temple pyrénéen. Il s'agit de la tour qui est adossée au chevet de l'œuvre architecturale. On a pris soin de la placer au même endroit où avait été érigée cette structure dans l'ancien édifice roman du Canigou. Cependant, il est curieux de remarquer

83. Jungmann, José Antonio, op. cit., p. 558-559 et note 54.

84. Ibidem., p. 618; RigheTti, Mario, op. cit., t. II, p. 281 et CABROL, Ferdinand et LECLERCQ, Henri, Vox, "Encens ", Dictionnaire d'Archéologie Chrétienne et de Liturgie, V, 1, Paris, 1922, cols. 2-21 et "Encensoir ", Dictionnaire..., V, 1, cols. 21-33.

85. STIRnEMANn, Patricia, op. cit., p. 174.

86. RigheTt, Mario, op. cit., t. I, p. 836.

87. Les Vierges n'ont pas toujours été représentées radieuses, à de multiples occasions, elles furent représentées sans les pommeaux d'huile et les poignées dans les mains, et leur nombre de trois n'est pas toujours avéré. On peut ainsi citer par exemple la scène de la Bible de Ripoll, Rome, Bibliothèque Apostolique Vaticane, Vat. Lat. Ms. 5729, fol. 370.

88. StiRnemann, Patricia, op. cit., p. 174. Sur la bénédiction la plus ancienne des cloches en Occident et son usage pour annoncer la mort de l'évêque dans le rite hispanique, voir : FÉroTIN, Marius, op. cit., cols. 112 et 140-141; CABROL, Ferdinand et LECLERCQ, Henri, Vox, "Cloche, clochette ", Dictionnaire d'Archéologie Chrétienne et de Liturgie, III, 2, Paris, 1914, cols. 1954-1977; HANI, Jean, El simbolismo del templo cristiano, Barcelone, 1997, p. 66-67 et MARCos CASQuERo, Manuel-Antonio, "El supersticioso mundo de las campanas ", Supersticiones, creencias y sortilegios en el mundo antiguo, Madrid, 2000, p. 81-108. 
qu'aux alentours de 1200 et dans une tour de cette taille, on n'a pas placé de cloches pour appeler les fidèles à la prière ${ }^{89}$, alors qu'il existe des exemples antérieurs de miniatures dans le domaine hispanique, comme par exemple avec l'église de Pergame dans le Beatus de Turin ${ }^{90}$.

Signalons enfin que tant la nef que l'entrée du Temple sont ornés de tentures. Les riches tissus et les couleurs vives étaient en effet fort appréciés. On dit d'ailleurs que la basilique du saint à Tours ${ }^{91}$ était ornée de la sorte grâce à d'importantes donations royales ${ }^{92}$. L'image miniature de saint Martin du Canigou semble s'inscrire dans ce contexte et l'espace sacré apparaît fastueux à cause de la solennité de ce jour.

Comme nous l'avons souligné, les prières des membres de la confrérie et l'offrande de l'encens l'élevaient vers le haut ${ }^{93}$, vers la Maiestas Christi, entourée par sainte Marie et saint Martin. Cette composition trinitaire émane de la Deesis byzantine ${ }^{94}$. Les trois figures possèdent un rôle de médiation face à la divinité. Saint Bernard le démontre bien avec ces mots : "Le Christ, dans son humanité est sans nul doute un fidèle et puissant médiateur entre Dieu et les Hommes " et il poursuit : " Nous avons besoin d'un médiateur pour rejoindre ce Médiateur et nous ne pouvons en trouver un meilleur que Marie ${ }^{95}$."

89. Cette fonction " d'appel " des cloches est bien définie par l'évêque Eustache de Thessalonique, lorsqu'au XII ${ }^{\mathrm{e}}$ siècle, suivant l'idée des pythagoriciens, il avait compris que " le bronze était l'unique élément doté de voix ", voir : MARCOS CASQUERO, Manuel-Antonio, op. cit., p. 155-156.

90. Torino, Biblioteca Nazionale Universitaria, Ms. I. II.1, f ${ }^{\circ} 62$ v. FERNÁNDEZ GonZÁLEZ, Etelvina, y Miguélez CAVERo, Alicia, " Die Mikroarchitecturen in den Darstellungen der 'Sieben Gemeinden von Asien' in den ikonographischen Zyklen der Apokalypse im Mittelalter ", Mikroarchitektur im Mittelalter. Ein gattungsübergreifendes Phänomen zwischen Realität und imgination, Germanisches Nationalmuseum Nürnberg (26-29 oct. 2005), Leipzig, 2008, p. 455-476. La basilique de Saint-Jacques-de-Compostelle devait avoir de magnifiques cloches. Alphonse VII, après l'incendie de 1117 avait fait construire de "bonnes et belles cloches ". Voir : FALQUE, Emma (éd.), Historia Compostelana, Madrid, 1994, lib. II, chap. LXXVII, p. 451-452.

91. GregorRe DE Tours, Historia Francorum, VI, 10. D’après : Lelong, Charles, La Basilique Saint-Martin-de-Tours, Tours, 1986, p. 18.

92. On dit de l'impératrice Adélaïde, qu'après l'incendie qui ravagea la basilique tourangelle, elle envoya pour orner l'autel de saint Martin, la moitié du manteau royal de son fils Otton, imitant ainsi la première Charité du Saint. Epitaphium Adalheidae, Monumenta Germaniae Historica Scriptores IV, 643, et LECOY DE LA MARCHE, Albert, op. cit., p. 476 et CORBET, Patrick, Les Saints ottoniens..., op. cit. Cf. supra note 3.

93. Les reliques de saint Martin accomplirent un curieux miracle grâce à l'encens. Grégoire de Tours raconte qu'une femme présenta un enfant sourd-muet devant la tombe du Saint. Elle se mit à prier longtemps et brûla de l'encens. Elle mit ensuite l'enfant dans la fumée qui montait vers le ciel et lui demanda s'il aimait cette odeur; l'enfant aussitôt guéri lui répondit : " oui ». Voir : GREgorius Turonensis, De miraculis Sancti Martini, 1. II, cap. XXXVIII, Patrologia Latina LXXI, col. 958.

94. Voir : "Deesis ", Lexikon der Christlichen ikonographie, t. 1, Rom, Freiburg, Basel, Wien, 1994, cols. 494-499 et RÉAU, Louis, Iconografía del arte cristiano. Iconografía de la Biblia. Nuevo Testamento, t. 1/vol. 2, Barcelone, 1996, p. 754-755.

95. SAINT BERNARD «Sermon du Dimanche dans l'Octave de l'Assomption ", Obras completas..., p. 394-417, en particulier, p. 395. 
Depuis le IV siècle, les références à Marie comme intercesseur sont nombreuses tant au sein de l'église byzantine qu'en Occident ${ }^{96}$. Bède le Vénérable en donne de nombreux exemples ${ }^{97}$. Le texte du Sacramentaire du rite hispanique est ainsi très éloquent à ce sujet ${ }^{98}$. Cependant, c'est saint Bernard qui s'est attaché le plus à souligner la figure de Marie comme intercesseur dans des lettres ${ }^{99}$ et des sermons ${ }^{100}$.

À gauche de la Maiestas, la figure mariale a été placée symétriquement à celle de saint Martin figuré en prélat. Les textes et la bibliographie spécifique des saints comme intercesseurs sont si abondants que nous choisirons une nouvelle fois, comme exemple ponctuel, l'œuvre de saint Bernard $^{101}$. Au Moyen Âge, les saints, en parfaits chrétiens, furent patrons, avocats et intercesseurs des mortels. Et « si durant leur vie ils éprouvaient de la pitié pour les pécheurs et priaient pour eux, maintenant ils intercèdent encore davantage en notre faveur devant le Père, car ils connaissent bien mieux que nous les misères, et dans cette patrie, la charité, au lieu de disparaître, augmente ${ }^{102}$ ".

96. RéAU, Louis, Op. cit., t. 1/vol. 2, p. 119-121; pour l'étude de Marie comme mediatrix, voir : Iogna-Prat, Dominique, "Le culte de la Vierge sous le règne de Charles le Chauve ", Les Cahiers de Saint-Michel de Cuxa, XXIII, (1992), p. 97-116; ID., " La Vierge et les ordines de couronnement des reines au IXe siècle ", Marie. Le culte de la Vierge dans la société médiévale, Paris, 1996, p. 100-106, et Images of the Mother of God. Perceptions of the Theotokos in Byzantium, Norfolk, 2004, p. 277-286.

97. BeDa Venerabilis, " Homélie sur les fêtes de l'Ascension ", Patrologia Latina, XCIV, col. 422 .

98. On peut lire dans ce codex : "Seigneur Jésus Christ qui honora ainsi la Vierge Marie jusqu'à ce qu'elle devienne l'intercesseur pour nous devant toi par la grâce de son Ascension ", Sacramentaire, Patrologia Latina, LXXXV, col. 407. Voir également : PRADO, German, Valoración y plan de reforma el Rito Mozárabe, Madrid, 1943, p. 113-114.

99. Saint Bernard dans sa lettre aux chanoines de Lyon : "Proclame sa grandeur pour avoir trouvé la grâce, comme médiatrice de sa salvation et restauratrice des siècles". Voir : SAINT BERNARD, "Lettre 117 ». Obras completas..., t. VII, p. 582-591, en particulier, p. 583 .

100. On insistera sur le sermon de la veillée de la naissance de Marie, connu aussi comme Acueducto; dans celui-ci, il est fait référence à la Vierge à plusieurs moments et elle est comparée à l'eau " céleste ", épithète qui est ici parfaitement justifié, voir : SAINT BERNARD "Sermon de la Naissance de Sainte Marie », Obras completas..., t. IV, p. 418-441, en particulier, p. 429; voir encore le texte du "Sermon du Dimanche dans l'Octave de l'Ascension ", Obras completas ..., t. IV, p. 394-417, en particulier, p. 395. Par la suite, d'autres qualificatifs similaires ont été utilisés, comme : pont, échelle du ciel, avocate, et d'autres encore. La Vierge fut ensuite saluée dans les litanies comme "Tour de David ", selon le Cantique des Cantiques $(4,4)$. Sa place au sein de cette composition sur la tour monastique du Canigou est très significative. Cette fonction médiatrice fut ratifiée, il n'y pas si longtemps, lors du Concile Vatican II. Voir : Concilio Vaticano II. Constituciones. Decretos. Declaraciones, Madrid, 1966, p. 110.

101. Voir : Delehaye, Hippolyte, Sanctus. Essai sur le culte des saints dans l'antiquité, Bruxelles, 1927.

102. Voir : SAINT BERnARD, "Sur la Veillée des apôtres Pierre et Paul », Obras completas..., t. Iv, p. 254-259, notamment, p. 255. Les qualificatifs de " grandissime médiateur " conférés par saint Victor. SAINT BERNARD, "Sur la naissance de saint Victor. Sermon 2 ", Obras completas..., t. III, p. 362-269. 
Concrètement, en référence à saint Martin, nous nous appuyons sur le passage suivant de la lettre de Sulpice Sévère au diacre Aurèle : "Cependant il me reste encore un espoir, le dernier, que ce que nous n'avons pu obtenir par nous-même, nous puissions le mériter grâce aux prières de Martin ${ }^{103}$."

Les deux figures, celle de Marie et celle du saint de Gaule, possèdent la même taille et adoptent la même attitude : un doigt d'une main qui pointe vers les fidèles et l'autre main vers le Christ. Elles montrent ainsi le lien de communication entre les hommes et la divinité dont nous venons de parler et cela est d'autant plus explicite dès lors que nous plaçons les deux images sur un plan distinct et devant celui de la Maiestas.

P. Stirnemann, en bon critique, voit dans ces deux figures le lien avec les espaces de l'église du Canigou, puisque la crypte fut consacrée à sainte Marie et l'église à saint Martin ${ }^{104}$. À ce moment de notre étude, on peut se demander à quel contexte spatial et à quelle structure peut faire référence cette composition parfaitement intégrée dans le tableau inférieur de la miniature. Il s'agit d'une vision céleste classique. C'est d'ailleurs pour cela que le programme iconographique semblerait valider son emplacement sur la voûte intérieure du chevet de l'église. Par ailleurs, la vision céleste était habituelle dans les illustrations de manuscrits et dans plusieurs pièces des objets et du mobilier liturgiques. Ainsi, par exemple, des icônes et des compositions similaires ornèrent, aux mêmes dates, un grand nombre de devants d'autel et de baldaquins de bois polychrome dans les milieux catalans et pyrénéens ${ }^{105}$. On pourra ainsi citer le magnifique baldaquin de Tost récemment restauré ${ }^{106}$.

Par ailleurs, pour en revenir à ce qui a été précédemment exposé, le dessin cruciforme généré par le cercle de l'éternité et qui est présent dans d'autres pièces de cet espace géographique ne cesse de susciter notre intérêt. À quoi renvoie cet élément? Il pourrait s'agir d'un simple châssis ou d'une partie de la structure du baldaquin à moins que cela ne soit un mode d'organisation spatiale destiné à ordonner les figures et les scènes qui ornent ces pièces. Il peut également s'agir d'un schéma de la croix avec la Maiestas superposée.

D'autre part, il est important de rappeler que, si l'on suit l'Évangile de Jean et certains poètes latins, l'usage des quatre monosyllabes pour nommer le Christ s'est popularisé : Lux, Rex, Pax, Lex. Son origine provient de l'époque carolingienne ${ }^{107}$. Ces noms ont été gravés sur les étroites

103. Vita, Epístola Secunda. Au diacre Aurèle, p. 179-183, en particulier, p. 183.

104. STIRnEMAnN, Patricia, op. cit., p. 175.

105. D'après le travail de Patricia Stirnemann et selon les hypothèses de Marcel Durliat, cette scène pourrait correspondre à une offrande de ce type, payée par les excédents de l'offrande de la Confrérie, comme le suggère le document de la fondation. Voir : STIRNEMANn, Patricia, op. cit., p. 177.

106. Voir : CASTIÑEIRAS, Manuel, "El baldaquí de Tost : una obra maestra de la pintura sobre taula ", El cel pintat. El Baldaquí de Tost, Vic, 2008, p. 33-54.

107. Favreau, Robert, "Rex, Lex, Lux, Pax. Jeux de mots et jeux de lettres dans les inscriptions médiévales ", Bibliothèque de l'École des Chartes, t. 161, 2003, p. 265-235. 
traverses des croix aniconiques où était placée au centre la Maiestas ${ }^{108}$. Ainsi, il semble difficile, au vu de ces réflexions, de déterminer l'origine et la fonction unique de cette structure cruciforme; il semblerait plus sage de proposer un syncrétisme de toutes les hypothèses avancées.

L'idéologie du programme iconographique qui nous intéresse ici remonte à des époques antérieures, et s'intègre dans différents domaines européens et dans le contexte royal. Le sens particulier et le caractère sacré des monarchies européennes durant le Moyen Âge et, plus particulièrement, pendant l'Empire, eurent des conséquences artistiques primordiales ${ }^{109}$. N'oublions pas que le roi médiéval est un roi pieux, et en tant que tel, il doit réaliser perpétuellement les gestes pieux pour la postérité ${ }^{110}$. Dans la miniature anglaise de l'école de Winchester, de la fin du $\mathrm{X}^{\mathrm{e}}$ siècle et au début du siècle suivant, nous avons deux exemples significatifs qui illustrent ces propos. Dans l'un d'entre eux, le roi Edgar, accompagné par la Vierge et saint Pierre, dont les incantations avaient consacré le monastère, offre le Cartulaire de New Minster (966) au Christ en Majesté entouré d'anges tenants ${ }^{111}$. L'autre exemple est extrait du Liber Vitae de New Minster, codex de miscellanées écrit vers $1031^{112}$. Dans cette illustration, les souverains, Knut et Emma, donnent une croix qu'ils placent sur l'autel. Pour sa bonne action, le monarque est couronné par un ange, tandis qu'un autre couvre la reine ${ }^{113}$. En haut, sur la mandorle, le Christ préside la céré-

108. Un des exemples les plus intéressants que nous trouvons sur un ivoire de l'école de Cologne, aux environs de 960-980, se trouve au Hessisches Landesmuseum de Darmstadt. Voir : JÜLICH, Theo, "Maiestas Domini ", Otto der Grosse. Magdeburg und Europa, fiche de catalogue IV. 82, Band, II, Katalog, Mainz, 2001, p. 310-312.

109. Ne pas oublier en ce sens l'influence que Byzance exerça sur le monde occidental. On utilisera l'exemple de l'ivoire conservé au château Sforza de Milan; sur cette pièce, la composition a ce même sens et les personnages royaux sont en prière : Otton II, Otton III et Théophano. Voir : CORBET, Patrick, " Les impératrices ottoniennes et le modèle marial. Autour de l'ivoire du château Sforza de Milan ", Marie. Le culte de la Vierge..., p. 109-134.

110. FERnÁNDEZ GonZÁlez, Etelvina, "La representación del rey en León y Castilla (ss. XIXII) ", Sacralités Royales en Péninsule Ibérique 2. Le Moyen Âge central, XI siècle-milieu du XIII siècle, (sous presse).

111. Dans le Cartulaire du roi Edgar pour le New Minster de Winchester, on commémore l'arrivée des bénédictins au monastère. London, British Museum, Cotton Ms. Vespasianus, A. VIII, $\mathrm{f}^{\circ} 2 \mathrm{v}^{\circ}$. Voir : Wormald, Francis, "Late anglo-saxon art: Some questions and suggestions ", dans p. 109-110, 179, 232-235, fig. 228; AlEXANDER, Jonathan James Graham, Brown, Thomas Julian, and GiBBS, Joan (éd.), Collected writings, I, Oxford, 1984, TEMPLE, Elzebieta, Anglo-Saxon manuscripts 900-1066 (A survey of manuscripts illuminated in the British Isles, 2), London, 1976, fiche de catalogue 16, p. 44; The Golden Age of Anglo-Saxon $A r t$, London, 1984, n 26, p. 47, pl. Iv et YARZA LuACES, Joaquín, " Las miniaturas del Libro de los Testamentos ", Liber Testamentorum Ecclesiae Ovetensis, Barcelone, 1995, p. 147-230, en particulier, p. 148-150 et fig. 10 .

112. London, British Museum, Stowe, Ms. 944, $\mathrm{f}^{\circ} 6$.

113. Les anges furent également considérés comme des intercesseurs. Saint Bernard s'appuie sur des traditions antérieures : "Les anges et les saints montent et descendent jusqu'à Lui (Dieu) car la tête et le corps sont un seul Christ ", SAINT BERNARD, "Sur la naissance de saint Jean Baptiste ", Obras completas..., t. IV, p. 238- 253, en particulier, p. 239 où il poursuit en ces termes : "Vous verrez les anges de Dieu monter et descendre pour le Fils de l'homme. Pour lui, ils ne souffrent aucune altération à monter ou descendre, car 
monie, accompagné par la Vierge et saint Pierre. Dans le tableau inférieur, les moines assistent au rite en regardant vers le haut ${ }^{114}$.

Dans le contexte hispanique, le Liber Testamentorum, cartulaire du premier quart du XII ${ }^{\mathrm{e}}$ siècle (fig. 3) est un exemple idoine; il contient les documents relatifs à la cathédrale de Saint-Sauveur d'Oviedo ${ }^{115}$. La miniature qui précède le testament d'Alfonse II le Chaste $\left(\mathrm{f}^{\circ} 6 \mathrm{v}^{\circ} \mathrm{A}\right)$ est une illustration exceptionnelle disposée en deux tableaux. Dans le tableau supérieur a été placée la Maiestas Domini, avec l'Alfa et l'Omega, dans la mandorle soutenue par des séraphins et des chérubins. Dans les angles apparaissent les images des quatre vivants. Dans les quatre coins, les apôtres sont abrités sous des arcades.

Il est clair que ce modèle de composition est à rapprocher de la façade du Saint Coffre d'Oviedo ${ }^{116}$. La zone supérieure est une allusion céleste d'où l'on contemple sur le tableau du bas le monde terrestre. Au centre de ce dernier, le monarque, accompagné de son armiger se signe à genoux, dans une posture de prière ou d'offrande avec le visage tourné vers la vision théophanique. Rappelons par ailleurs que dans le testamentum du souverain en 812 , la donation est relatée en ces termes :

"Pour autant, Seigneur, sur ton autel sacré fondé dans ladite église (San Salvador) j'offre pour la gloire de ton nom l'atrium qui entoure ta maison, la ville entière d'Oviedo ${ }^{117}$. "

Si l'on tient compte de ce texte, on ne pourra omettre le fait que le miniaturiste ait voulu volontairement laisser dans cette composition le portrait

ils sont envoyés continuellement afin d'aider ceux qui doivent hériter du salut et ils ne cessent jamais d'être en présence de sa Majesté ", SAINT-BERnARD, "Dévotion de l'Église. Sermon 5 », Obras completas..., t. IV, p. 602-616, en particulier, p. 609.

114. Voir : WoRmald, Francis, op. cit., p. 248-259 et fig. 251; TEMPLE, Elzebieta, op. cit., fiche de catalogue 78, p. 95-96 et YARZA LUACES, Joaquín, "Las miniaturas... ", p. 150-151 et fig. 11, et BACKHOUSE, Janet, "Liber Vitae von New Minster ", Heinrich der Löwe und seine Zeit. Herrschaft und Repräsentation der Welfen 1125-1235, Band 1, Katalog, fiche de catalogue, D-115, Münich, 1995, p. 320-322.

115. Oviedo, Archives de la Cathédrale, Ms. 1. Voir : Yarza LuACEs, Joaquín, " Las miniaturas... ", p. 162-170 et 220-221 ; SANZ FuENTES, María Josefa, "Liber Testamentorum ", Maravillas de la España medieval. Tesoro sagrado y monarquía, tomo I, Madrid, 2001, fiche de catalogue 41, p. 121-122, où sont présentes les dernières références bibliographiques sur l'œuvre; FERNÁNDEZ GonZÁlEz, Etelvina, " El retrato regio en los Tumbos de los tesoros catedralicios ", Maravillas de la España medieval. Tesoro sagrado y monarquía, t. I, p. 41-54, où est analysé le " portrait pieux ", FERNÁNDEZ GONZÁLEZ, Etelvina, "Regalia, símbolos episcopales y el ajuar litúrgico en el Liber Testamentorum de la catedral de Oviedo ", Imágenes del poder en la Edad Media, Estudios in memoriam del Prof. Dr. Fernando Galván Freile, t. II (coord. Etelvina Fernández González), León, 2010, p. 163-181.

116. Fernández GonzÁlez, Etelvina, "El Arca Santa de Oviedo y sus precedentes. De Alfonso II a Alfonso VI ", Actas del Congreso Internacional "Alfonso VI y su legado", celebrado en Sahagún (León); del 29 al 31 de octubre de 2009. IX Centenario de Alfonso VI (1109-2009), León, 2012, p. 311-343.

117. Sur le testamentum d'Alphonse II le Chaste, voir l'étude récente de SANz FuENTES, María Josefa, "Estudio codicológico, paleográfico y diplomático », Testamento de Alfonso II el casto. Estudio y contexto histórico, Oviedo, 2005, p. 51-81. 
d'Alphonse II au moment de faire l'offrande devant l'autel de la cathédrale d'Oviedo. Dans les deux tableaux latéraux, sainte Marie et saint Michel sont présents comme médiateurs, et ce dernier est d'ailleurs représenté comme chef des milices célestes puisqu'il apparaît avec une lance et menaçant le dragon ${ }^{118}$.

Dans cette scène du Liber Testamentorum, nous trouvons la double vision présente dans la Maiestas avec l'image royale. À travers elle, on remarque que la mise en valeur symbolique de la miniature hispanique, malgré tout le symbolisme qu'elle peut renfermer, s'inscrit davantage dans la lignée des exemples anglais - où le monarque se représente comme un roi pieux - qu'au sein des programmes d'Europe Centrale où l'on insiste davantage sur le sens politico-religieux hérité de l'empire carolingien.

Dans une autre étude, nous nous intéresserons aux références faites à l'espace sacré dans la miniature. Nous pensons, comme le professeur Sanz Fuentes, que les trois édifices érigés sous les auspices du monarque s'y reflètent ${ }^{119}$. Au vu des compartiments spatiaux et des différents thèmes iconographiques analysés, on remarque qu'il s'agit d'un programme iconique bien planifié. Au centre la Maiestas et les apôtres peuvent être interprétés comme la représentation symbolique de la basilique du Sauveur; à droite du Christ se trouve sainte Marie, en souvenir de l'église de Sainte Marie du roi Chaste, érigée par ce monarque au nord du temple et qui est aujourd'hui disparue; à ses pieds a été édifié le panthéon royal. Au sud de la basilique du Sauveur se dresse l'oratoire royal connu comme la Chambre Sainte et, à l'intérieur de celui-ci, la chapelle de saint Michel, le trésor où étaient conservés les biens les plus précieux du royaume : les reliques, les regalia et le Liber Testamentorum ${ }^{120}$ (fig. 4).

Il semble clair que les invocations, les images, et leur emplacement sont des éléments suffisants pour se référer symboliquement à l'architecture et aux lieux saints de la ville d'Oviedo au début du IX ${ }^{\mathrm{e}}$ siècle. C'est dans ce contexte qu'on doit interpréter la miniature du parchemin de Saint-Martin du Canigou, mais avec une nouveauté notable, puisqu'on passe de la piété individuelle incarnée par le roi asturien à une autre formule où les protagonistes sont un groupe de fidèles dévots de saint Martin.

Nous pensons que, dans ce programme iconographique, on raconte en image l'histoire d'un fait : celui de la création de la confrérie. C'est l'idée recherchée dans ce " portrait collectif ", un " portrait corporatif " au sein

118. Comme il a déjà été précisé, sur les reliefs du coté droit du Coffre Saint, on trouve la figure de saint Michel menaçant de sa lance le dragon. Voir : FERNÁNDEz GonzÁLEz, Etelvina, "El retrato regio... ", p. 44-46 et ID., " El Arca Santa de Oviedo y sus precedentes... ".

119. SANZ FuENTES, María Josefa, " Estudio paleográfico ", Liber Testamentorum Ecclesiae Ovetensis, Barcelona, 1995, p. 93-143, notamment, p. 134.

120. FERnÁNDEZ GonZÁlEz, Etelvina, "El retrato regio... ", p. 46. Sur les espaces de l'Urbs Regia, voir : Carrero SAnTAmaría, Eduardo, "La "Ciudad Santa" de Oviedo, un conjunto de iglesias para la memoria del rey ", Hortus Artium Medievalium, 13/2, 2007, p. 375-389. 
Figure 4 - Oviedo. Plan de la ville à l'époque d'Alphonse II (d'après Uría Ríu. Archives d'Ayalga)

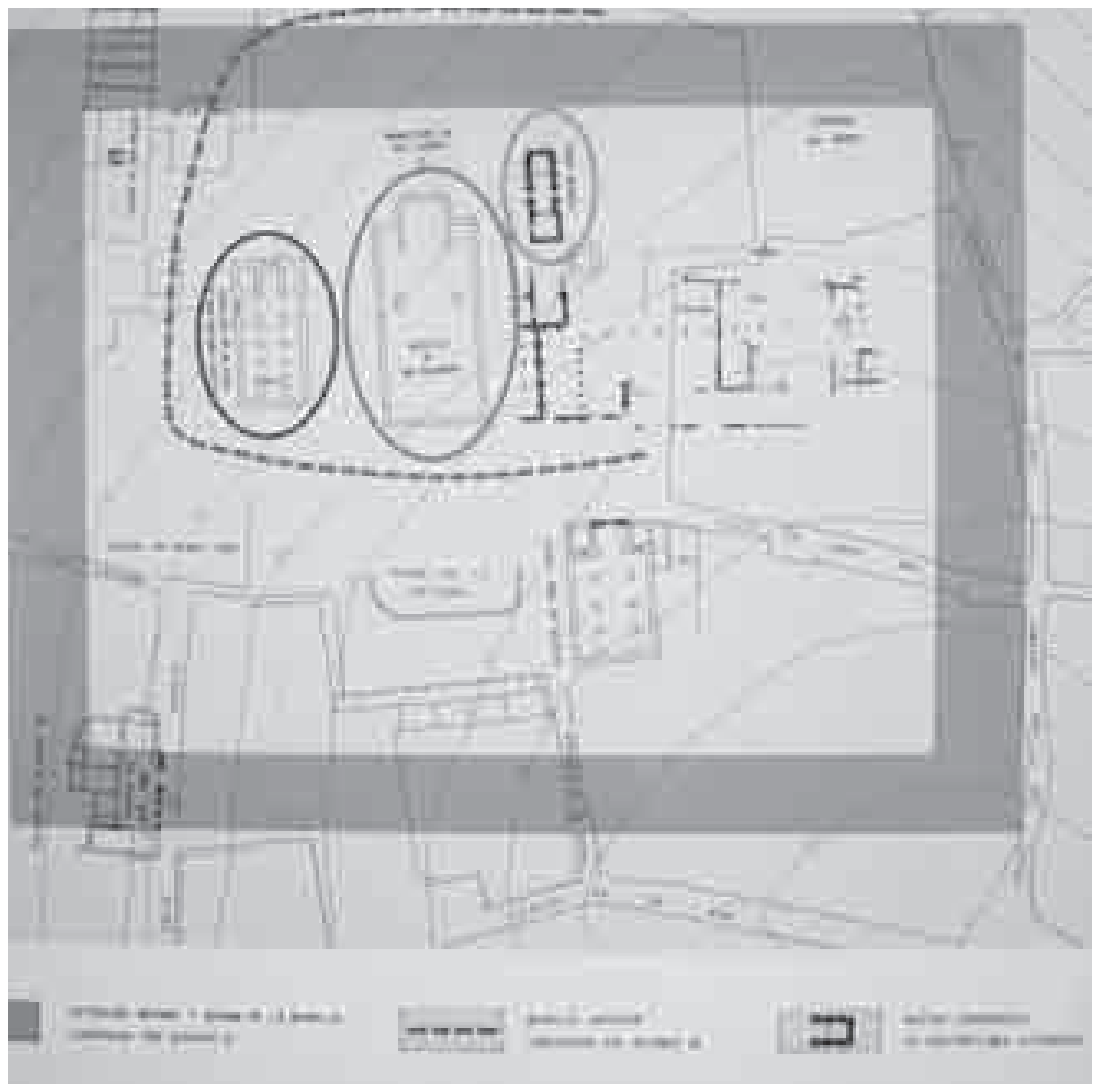

d'une organisation spatiale qui est conventionnelle et symbolique comme il convenait dans la plastique du début du XII ${ }^{\mathrm{e}}$ siècle et qui tendrait à devenir "véridique ". 